\title{
Pengaruh Air Lahan Gambut di Kalimantan Selatan terhadap Beton Porous dengan Penambahan Fly Ash
}

\author{
Eka Purnamasari*1, Muhammad Saukani², Fitriani Ridzeki ${ }^{3}$ \\ ${ }^{1,2}$ Universitas Islam Kalimantan MAB, Banjarmasin \\ ${ }^{3}$ Program Studi Teknik Sipil, FT Uniska MAB, Banjarmasin \\ E-mail: *eka.ftsuniska@gmail.com
}

Received 02 September 2020; Reviewed 19 October 2020; Accepted 13 July 2021

Journal Homepage: http://jurnal.borneo.ac.id/index.php/borneoengineering

\begin{abstract}
Research on the compressive strength of porous concrete using coarse aggregate with the addition of pozzolan fly ash material and immersed in peat water aims to provide information to the community, especially those in areas surrounded by peat/swampland that fly ash can actually be used as a building material. The method used in this research is experimental in the laboratory. The research variables here are the portion of the addition of fly ash in several variations of the portion of the non-sand concrete mixture and the effect of immersion using peatland water. The compressive strength of porous concrete decreased during the soaking treatment with peat water. In the porous concrete sample treated with swamp water, the compressive strength of the concrete decreased by $10.28 \%$ compared to the porous concrete sample soaked with PDAM water. The compressive strength of porous concrete with $10 \%$ fly ash soaked with peat water is $6.89 \mathrm{MPa}$ and the compressive strength of porous concrete with $20 \%$ fly ash soaked with peat water is 7.85 Mpa. The crack pattern that was occurred due to the spread of stress on the specimen due to the grip binding process on the test object and also affected the aggregate homogeneity of the concrete. In the model, the treatment of immersion with PDAM water and peat swamp water is based on the results of the research on the crack pattern that was occurred namely cracks on the side ends.
\end{abstract}

Keywords: fly ash; peat water; compressive strength; concrete; porous

\begin{abstract}
Abstrak
Penelitian terhadap kuat tekan beton beton porous yang menggunakan agregat kasar dengan tambahan material pozzolan fly ash dan direndam dalam air gambut bertujuan untuk memberikan informasi kepada masyarakat khususnya yang wilayahnya dikelilingi oleh lahan gambut bahwa fly ash ternyata dapat digunakan sebagai bahan bangunan. Selain itu menumbuhkan kesadaran masyarakat untuk dapat seluas mungkin memanfaatkan limbah pembakaran batu bara (fly ash) misalnya diplikasikan untuk campuran bahan bangunan seperti beton dan mortar. Metode yang digunakan dalam penelitian ini adalah eksperimental di laboratorium. Variabel penelitian di sini adalah porsi penambahan fly ash pada beberapa variasi porsi campuran beton non pasir dan pengaruh perendaman menggunakan air lahan gambut. Kuat tekan beton porous mengalami penurunan saat perawatan perendaman dengan air gambut. Pada sampel beton porous yang diberi perawatan perendaman dengan air rawa mengalami penurunan kuat tekan beton sebesar 10,28\% dibandingkan dengan sampel beton porous yang direndam dengan air PDAM. Kuat tekan beton porous dengan fly ash 10\% yang direndam dengan air gambut yaitu sebesar 6,89 Mpa dan uat tekan beton porous dengan fly ash $20 \%$ yang direndam dengan air gambut yaitu sebesar 7,85 Mpa. Pola retakan yang terjadi dikarenakan penyebaran tegangan pada benda uji akibat proses ikat pegangan pada benda uji dan juga berpengaruh terhadap homogenitas agregat penyusun beton. Pada model yang dilakukan perawatan perendaman dengan air PDAM dan air rawa gambut berdasarkan hasil penelitian pola retak yang terjadi yaitu retakan pada ujung samping.
\end{abstract}

Kata kunci: fly ash; air gambut; kuat tekan; beton; berpori 


\section{Pendahuluan}

Berdasarkan penelitian Trisnoyuwono (2015), bahwa fly ash dapat meningkatkan kinerja beton sekaligus menggantikan sebagian porsi semen. Fly ash sebagai hasil sampingan dari pembakaran batu bara pada instalasi PLTU sebagai bahan tambah untuk beton non pasir diharapkan dapat mengurangi penggunaan semen dan memperbaiki sifat workability beton non pasir yang rata - rata memiliki nilai slump yang rendah dan berdampak terhadap kemudahan dalam pengecoran dan pemadatan.

Kalimantan selatan telah berdiri unit PLTU yang menggunakan batu bara sebagai bahan bakarnya, yang menghasilkan limbah fly ash, dimana limbah tersebut belum sama sekali dimanfaatkan oleh masyarakat. Pemanfaatan fly ash sebagai bahan bangunan dapat secara langsung mengurangi penimbunan limbah, mengurangi polusi udara dan sifatnya yang dapat menggantikan sebagian porsi semen memberikan solusi untuk meminimalkan penggunaan semen sehingga biaya konstruksi dapat ditekan.

Beton non pasir adalah jenis beton ringan yang tidak menggunakan agregat halus (pasir), beton tersebut memiliki beberapa keunggulan yang dominan yaitu porositas yang tinggi, bobot yang ringan, bersifat isolasi panas, tidak memiliki daya kapiler, susutnya yang kecil, tidak mudah bersegregasi pada saat pengecoran dan kebutuhan semen yang sedikit (Tjokrodimuljo, 2004). Tidak menggunakan pasir dalam campurannya maka kebutuhan semen akan lebih sedikit dibanding beton normal. Selain keunggulan tesebut terdapat kelemahan pada sifat fisik beton segar, yaitu workability beton non pasir yang rendah. Masalah muncul di saat kegiatan pengecoran ke dalam cetakan kolom atau balok, ukuran cetakan dan formasi tulangan yang terbatas akan menyulitkan pemadatan. Masalah akan bertambah jika produk ini dilaksanakan di lapangan oleh pekerja yang kurang cakap (tidak) terbiasa membuat adonan beton yang terlampau encer).

Penelitian terhadap kuat tekan beton beton non pasir yang menggunakan agregat kasar dengan tambahan material pozzolan fly ash dan direndam dalam air gambut/rawa bertujuan untuk memberikan informasi kepada masyarakat khususnya yang di wilayahnya dikelilingi oleh lahan gambut/rawa bahwa fly ash ternyata dapat digunakan sebagai bahan bangunan. Selain itu menumbuhkan kesadaran masyarakat untuk dapat seluas mungkin memanfaatkan limbah pembakaran batu bara (fly ash) misalnya diaplikasikan untuk campuran bahan bangunan seperti beton dan mortar. Kemudian akhirnya masyarakat juga memiliki pengetahuan bahwa tidak selamanya beton itu harus dicampur dengan pasir, berbobot berat dan kedap air.

Menurut Harber (2005), Pengembangan bahan beton non pasir di Indonesia telah dimulai sejak lama. Tercatat beberapa penelitian dengan menggunakan variasi jenis agregat untuk diaplikasikan sebagai batako, rumah cetak, jalan lingkungan sampai dengan barang kerajinan. Penelitian terkait pemanfaatan agregat ALWA sebagai beton non pasir dirintis oleh Tjokrodimuljo dan Basewed, di tahun 1997 serta Wahyudi, pada tahun 1998. Sedangkan pengembangan ALWA sebagai agregat telah dilakukan oleh Puslitbang Permukiman, Balitbang Pekerjaan Umum, Departemen Pekerjaan Umum sejak tahun 70-an.

Struktur beton non pasir sangat berbeda dengan beton konvensional dalam pengertian bahwa pasta semen yang mengikat agregat menjadi satu berupa lapisan yang tipis. Ketika dilakukan pemadatan maka akan membuat partikel - partikel agregat menjadi lebih menyatu, sehingga pasta semen keluar dari bidang kontak dan menyelimuti partikel - partikel agregat tersebut. Menurut Mehta, P. K., \& Monteiro, P. J. (2014), agregat adalah bahan granular, seperti pasir, kerikil, batu pecah, atau 
limbah konstruksi dan pembongkaran yang digunakan dengan penyemenan media untuk menghasilkan beton atau mortar. Istilah agregat kasar mengacu pada partikel agregat lebih besar dari 4,75 mm (saringan No. 4).

Karakteristik utama yang diharapkan dari beton non pasir adalah sifat porositasnya, penggunaan pasta semen yang berlebihan (porsi campuran semen - agregat lebih kecil 1:5) akan mengurangi sifatnya tersebut. Proses produksi beton porsi air harus menjadi perhatian utama. Porsi air yang berlebihan akan menyebabkan pasta semen yang encer dan akan sulit merekat ke permukaan agregat. Sehingga untuk praktisnya Faktor Air Semen (FAS) yang digunakan tidak melebihi angka 0,5. Karena adanya pembatasan kadar air dalam campuran menyebabkan adonan menjadi sangat kental (slump di bawah $5 \mathrm{~cm}$ ). Ukuran bekisting yang terbatas menyulitkan pemadatan. Sehingga dibutuhkan bahan tambahan yang dapat meningkatkan kelecakan tanpa air penambahan lagi.

Kuat tekan beton non pasir dipengaruhi oleh jenis, bentuk agregat gradasi agregat, rasio volume semen - agregat dan Faktor Air Semen (FAS). Pada umumnya agregat kasar yang dipakai berukuran $10-20 \mathrm{~mm}$, walaupun ukuran yang lain dapat pula dipakai. Pemakaian agregat dengan gradasi rapat dan bersudut (batu pecah) akan menghasilkan beton non pasir yang kuat tekan dan berat jenisnya sedikit lebih tinggi daripada yang memakai agregat seragam dan bulat (Tjokrodimuljo, 2004).

Fly ash (abu terbang) adalah material yang berasal dari sisa pembakaran batu bara yang tidak terpakai. Pembakaran batu bara kebanyakan digunakan pada pembangkit listrik tenaga uap. Produk limbah dari PLTU tersebut mencapai 1 juta ton per tahun (Paul Nugraha \& Antoni, 2007). Material ini mempunyai kadar bahan semen yang tinggi dan mempunyai sifat pozzolanik. Kandungan fly ash sebagian besar terdiri dari silikat dioksida $\left(\mathrm{S}_{\mathrm{i}} \mathrm{O}_{2}\right)$, aluminium $\left(\mathrm{Al}_{2} \mathrm{O}_{3}\right)$, besi $\left(\mathrm{Fe}_{2} \mathrm{O}_{3}\right)$ dan kalsium $(\mathrm{CaO})$, serta magnesium, potassium, sodium, titanium dan sulfur dalam jumlah yang lebih sedikit (Paul Nugraha \& Antoni, 2007). Sifat dasar abu terbang yang penting adalah sifat pengerasan sendiri yang menyerupai sifat semen. Abu terbang akan mengeras dengan bertambahnya waktu, karena itu kekuatannya juga akan meningkat.

Penggunaan bahan tambah pengganti sebagian semen saat ini telah banyak diteliti dan digunakan sebagai campuran mortar maupun beton. Menurut Saukani dan Arief (2018) bahwa mortar geopolimer yang disintesis mampu menahan adanya perubahan suhu secara mendadak. Oleh sebab itu mortar geopolimer dengan bahan abu layang/kaolin tatakan dapat digunakan sebagai material refraktori. Geopolimer dari fly ash dan tanah liat kaolin alami dari Tatakan, Kalimantan Selatan, Indonesia telah berhasil dihasilkan dengan penggunaan rendahnya konsentrasi larutan alkali. Natrium hidroksida, sebagai larutan alkali, memainkan peran penting dalam meningkatkan kekuatan kompresif dan mengurangi porositas (Saukani et.al, 2019). Secara ekonomi, hal ini memungkinkan adanya pengurangan biaya dengan menghemat jumlah semen yang digunakan. Sedangkan secara teknis, bahan tambah dapat berfungsi sebagai pengisi dalam campuran dan memperbaiki workability. Pemakaian bahan tambah juga memberikan keuntungan di bidang ekologi karena berpotensi mengurangi polusi udara dan air akibat penumpukan bahan ini dalam jumlah besar.

Pada penelitian sebelumnya, perbandingan volume semen dan agregat kasar yang digunakan dalam pembuatan campuran beton non pasir adalah $1: 4,1: 6$ dan $1: 8$ dengan nilai faktor air semen tetap yaitu sebesar 0,40 dengan porsi penambahan fly ash sebanyak $0 \% ; 10 \%$ dan 20\% terhadap berat semen (Diarto Trisnoyuwono, 2015). 
Menurut Agus dan Subiksa. (2008), lahan gambut umumnya mempunyai tingkat kemasaman yang relatif tinggi dengan kisaran $\mathrm{pH} 3$ - 5. Ditemukan bahwa tindakan serangan asam tergantung pada jenis asam dan kelarutan garam kalsium yang terbentuk (Goyal et.al, 2009). Penelitian ini dilakukan bertujuan untuk mengetahui hasil pengujian kuat tekan beton, diharapkan agar dapat mengetahui pengaruh perendaman dengan menggunakan air lahan gambut yang berada di Kalimantan Selatan terhadap kuat tekan beton porous dengan penambahan fly ash sebagai filler.

\section{Metode Penelitian}

Metode yang digunakan dalam penelitian ini adalah eksperimental di laboratorium. Variabel penelitian di sini adalah porsi penambahan fly ash pada beberapa variasi porsi campuran beton non pasir dan pengaruh perendaman menggunakan air lahan gambut. Terhadap varibel terebut akan dianalisis pengaruh penambahan fly ash pada beberapa variasi porsi bahan penyusun beton porous dan pengaruh perendaman menggunakan air lahan gambut yang menghasilkan derajat workability campuran yang memenuhi standar (nilai slump berkisar antara $10-15 \mathrm{~cm}$ ) .

Pembuatan benda uji hingga pengujian benda uji dilakukan di Laboraturium Struktur dan Bahan Program Studi Teknik Sipil Fakultas Teknik Kampus UNISKA MAB Banjarmasin

Pengujian kuat tekan (compressive strength) beton dilakukan untuk mengetahui berapa besar kekuatan tekan beton dengan umur sesuai dengan yang telah disyaratkan. Umur yang bisaa diuji adalalah umur 28 hari. Benda uji diletakkan pada mesin uji tekan dan diberi beban hingga beban maksimum yang dapat diterima benda uji. Cetakan benda uji yang digunakan untuk pengujian ini dapat berupa silinder.

Cetakan benda uji berupa silinder dengan diameter $152 \mathrm{~mm}$ dan tinggi $305 \mathrm{~mm}$. Cetakan diisi dengan adukan beton dalam 3 lapis, setiap lapis dipadatkan dengan 25 kali tusukan secara merata, setelah itu permukaan beton diratakan dan ditutup dengan bahan kedap air.

Perawatan beton adalah suatu pekerjaan menjaga agar permukaan beton selalu segar, lembab sampai beton dianggap cukup keras. Hal ini dimaksudkan untuk menjamin proses hidrasi semen berlangsung dengan sempurna. Selain itu perawatan juga mengurangi penyusutan akibat penguapan air berlebihan sehingga timbulnya retakan retakan dapat dihindari dan mutu beton tetap terjamin.

Uji kuat tekan beton porous dilakukan pada saat umur beton 28 hari. Faktor pengali untuk umur beton 28 hari adalah 1,00. Ada 6 jenis model sampel beton porous yang diteliti yaitu BP1A yaitu beton perawatan perendaman dengan air PDAM, BP1B yaitu beton perawatan perendaman dengan air gambut, BP2A yaitu beton porous dengan fly ash $10 \%$ dengan perawatan perendaman menggunakan air PDAM, BP2B yaitu beton porous dengan fly ash 10\% dengan perawatan perendaman menggunakan air gambut, BP3A yaitu beton porous dengan fly ash $20 \%$ dengan perawatan perendaman menggunakan air PDAM dan BP3B yaitu beton porous dengan fly ash $20 \%$ dengan perawatan perendaman menggunakan air gambut.

Air gambut yang digunakan dalam penelitian ini adalah air lahan gambut yang terdapat dikawasan kota Banjarmasin, dengan kualitas air didaerah rawa mengandung $\mathrm{pH}$ yang tinggi dengan, yaitu 34.

Bahan-bahan yang digunakan dalam melakukan penelitian adalah:

1. Agregat kasar yang digunakan berasal dari daerah Handil Bakti, Banjarmasin Provinsi Kalimantan Selatan dengan ukuran agregat $1 \mathrm{~cm}-2 \mathrm{~cm}$. yaitu agregat yang tertahan saringan 
nomer $1 / 2$ " dengan ukuran setiap lubangnya adalah $12,7 \mathrm{~mm}$ dan tidak lolos saringan nomer $3 / 8$ " atau setiap ukuran lubangnya adalah $9,6 \mathrm{~mm}$.

2. Semen yang digunakan dalam penelitian ini adalah semen jenis PPC (Portland Pozzolan Cement) tipe I merk Tiga Roda.

3. Abu Terbang (Fly ash) berasal dari Pembangkit Listrik Tenaga Uap (PLTU) Asam-Asam Kalimantan Selatan.

4. Air yang digunakan di laboraturium berasal dari air PDAM.

5. Air lahan gambut yang digunakan di laboraturium berasal dari lahan gambut yang berada disekitar kota Banjarmasin.

6. Cairan pelumas yang digunakan untuk melapisi cetakan sebelum benda uji dicetak agar setelah beton mengeras beton tersebut mudah dilepaskan dari cetakannya.

Adapaun diagram alir penelititian dapat di lihat pada gambar 1 dibawah ini,

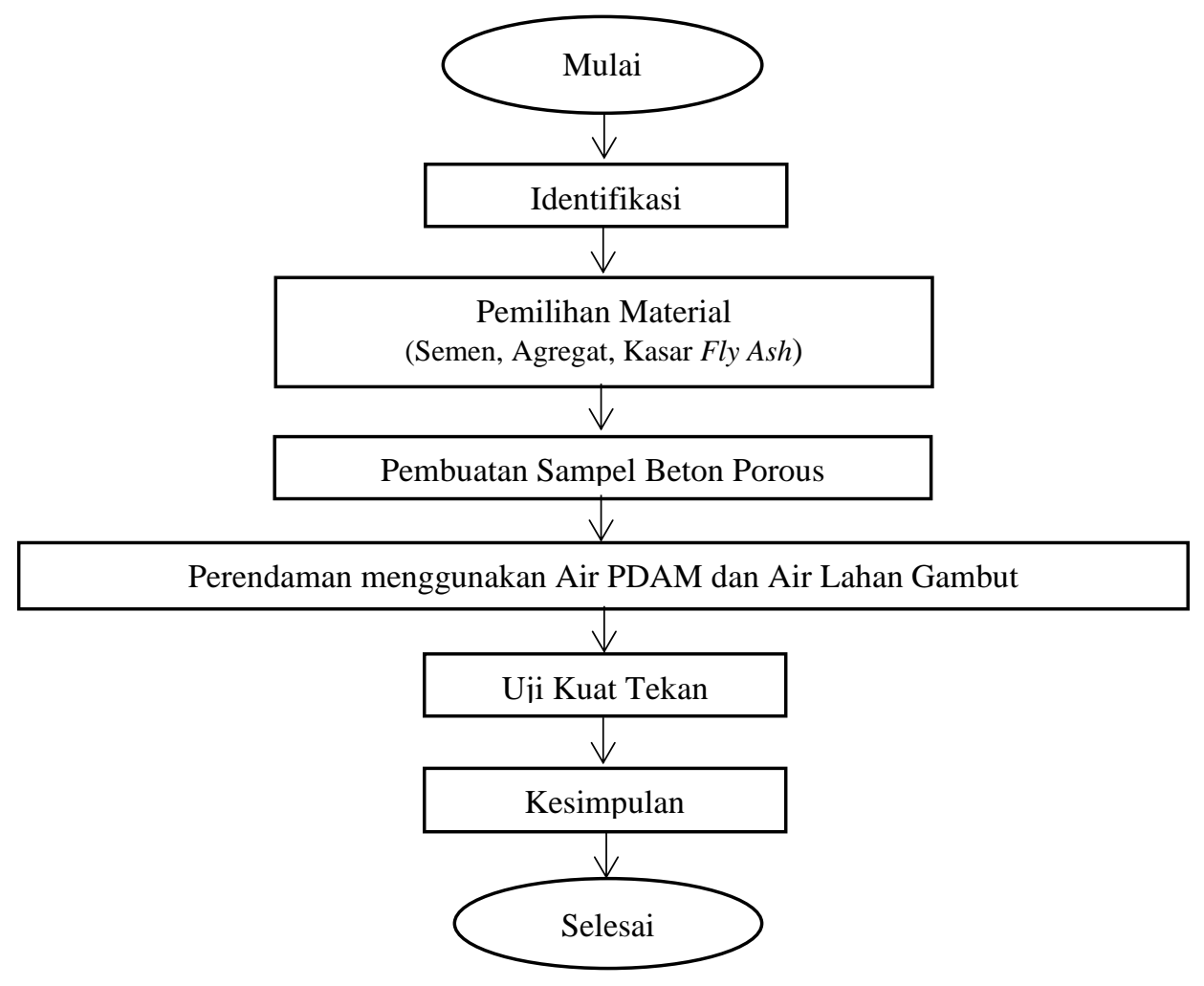

Gambar 1 Diagram Alir Penelitian

\section{Hasil dan Pembahasan}

Metode perawatan yang digunakan dalam penelitian ini adalah dengan cara direndam dalam bak perendam berisi air pada temperatur suhu ruangan. Perawatan dimulai pada hari kedua sampai satu hari sebelum dilakukan pengujian. Perawatan yang dilakukan pada penelitian ini menggunakan air PDAM dan air gambut. Kuat tekan beton porous pada beton dengan menggunakan agregat kasar yang berasal dari daerah Handil Bakti dengan rasio variasi jumlah fly ash dan metode perendaman adalah seperti Tabel 1 berikut ini. 
Tabel 1 Perbandingan Kuat Tekan Beton Porous

\begin{tabular}{cccccc}
\hline $\begin{array}{c}\text { No } \\
\text { Urut }\end{array}$ & $\begin{array}{c}\text { Benda } \\
\text { Uji }\end{array}$ & $\begin{array}{c}\text { Varian } \\
\text { Fly } \text { Ash }\end{array}$ & $\begin{array}{c}\text { Kuat Tekan } \\
\text { Rata-Rata }\end{array}$ & Jenis Air & Perendaman \\
\hline 1 & BP1A & $0 \%$ & 6,22 & $\begin{array}{c}\text { PDAM } \\
\text { Air } \\
\text { Gambut }\end{array}$ & 28 Hari \\
2 & BP1B & $0 \%$ & 5,06 & Hari \\
3 & BP2A & $10 \%$ & 6,56 & $\begin{array}{c}\text { PDAM } \\
\text { Air }\end{array}$ & 28 Hari \\
4 & BP2B & $10 \%$ & 6,89 & $\begin{array}{c}\text { Gambut } \\
\text { PDAM }\end{array}$ & 28 Hari \\
5 & BP3A & $20 \%$ & 7,47 & $\begin{array}{c}\text { Air } \\
\text { Gambut }\end{array}$ & 28 Hari \\
6 & BP3B & $20 \%$ & 7,85 & & \\
\hline
\end{tabular}

Dari Tabel 1 dapat dilihat bahwa kuat tekan beton porous tanpa penambahan fly ash mengalami penurunan saat perawatan perendaman dengan air gambut. Adapun yang terjadi saat pengujian kuat tekan tertinggi terjadi pada beton porous yang diberikan perawatan perendaman dengan menggunakan air PDAM yaitu sebesar 6,22 MPa. Pada benda uji beton porous dengan penambahan fly ash dengan varian 10\% dan $20 \%$ terjadi kenaikan kuat tekan dibandingkan dengan tanpa penambahan fly ash. Hal ini terlihat pada perbandingan antara kuat tekan beton porous pada benda uji BP1A, BP2A dan BP3A yang dilakukan perawatan dengan air PDAM.

Pada sampel beton porous tanpa penambahan fly ash yang diberi perawatan perendaman dengan air rawa mengalami penurunan kuat tekan beton sebesar 10,28\% dibandingkan dengan sampel beton porous yang direndam dengan air PDAM. Sedangkan terjadi hal sebaliknya pada beton porous yang diberikan penambahan fly ash, dari hasil pengujian kuat tekan beton porous dengan variasi penambahan fly ash 10\% yang direndam dengan air gambut yaitu sebesar 6,89 Mpa dan kuat tekan beton porous dengan variasi penambahan fly ash 20\% yang direndam dengan air gambut yaitu sebesar 7,85 Mpa. Hal ini terlihat pada perbandingan antara model BP2A, BP2B, PP3A DAN $\mathrm{BP} 3 \mathrm{~B}$, dimana terjadi kenaikan kuat tekan saat beton porous dengan penambahan fly ash dirawat dengan perendaman menggunakan air lahan rawa yang diambil dari sekitar daerah kota Banjarmasin dimana perbandingan tersebut bisa dilihat pada gambar 2.

Dapat dilihat bahwa beton porous yang diberi penambahan fly ash mampu memperbaiki atau meningkatkan kinerjanya. Kuat tekan beton porous yang dihasilkan pada variasi fly ash sebesar $10 \%$ dan $20 \%$ yang lebih tinggi jika dibandingkan dengan atau tanpa penambahan fly ash, ini terjadi karena reaksi pozzolanic antara fly ash dan matriks semen dapat meningkatkan kekuatan ikatan dengan agregat. Terbukti bahwa fly ash dapat menggantikan sebagian porsi semen didalam campuran, pengujian menunjukkan penambahan variasi jumlah fly ash dapat meningkatkan kuat tekan benda uji beton porous. Dengan demikian ini adalah sisi positif dari penggunaan limbah yang dapat pula dimanfaatkan untuk bahan bangunan.

Menurut SNI 03-2461-2002 tentang spesifikasi agregat ringan untuk beton ringan struktural, kuat tekan beton ringan untuk aplikasi elemen struktural bangunan memiliki rentang antara $17 \mathrm{MPa}-28$ MPa. Berdasarkan hasil pengujian maka benda uji beton non pasir dengan porsi semen - agregat 1 : 4 yang ditambahkan fly ash $10 \%$ dan $20 \%$ dengan kuat tekan 6,5 MPa dan 7,4 MPa maka hasil pengujian ini belum dapat diaplikasikan untuk elemen struktural bangunan. 


\section{Kuat Tekan Rata-Rata}

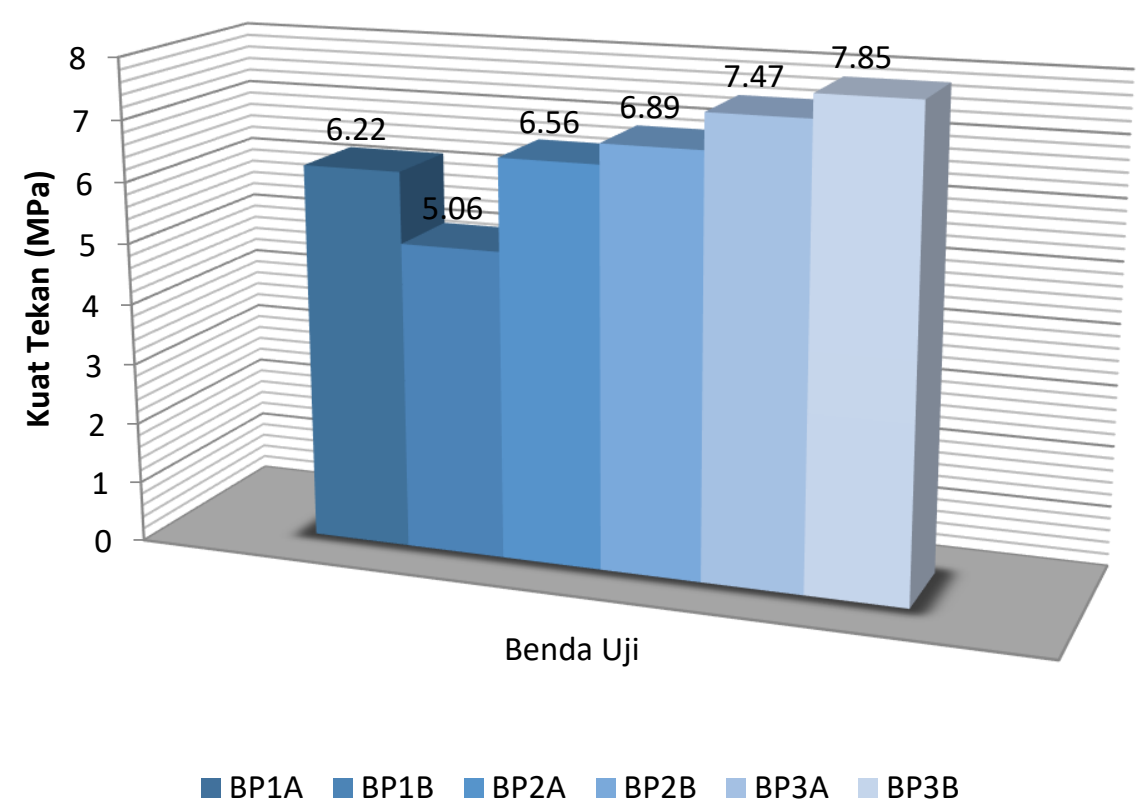

Gambar 2 Grafik perbandingan kuat tekan beton porous

Menurut SNI 03-6861.1-2002 untuk kuat tekan di bawah 17 MPa tentang spesifikasi bahan bangunan bagian a (bahan bangunan bukan logam) khususnya untuk material bata beton berlubang yang meperlihatkan persyaratan fisis dimana memiliki rentang kuat tekan yang disyaratkan yaitu dari tingkat mutu 1-4 nilainya sebesar $7 \mathrm{MPa}-2 \mathrm{MPa}$, maka bahan porous masih memenuhi syarat untuk digunakan sebagai bata beton pejal dan bahan bata beton (batako) sesuai standar dalam SNI 03-6861.1-2002 yang telah mensyaratkan rentang kuat tekannya dari 2,5 $\mathrm{MPa}-10 \mathrm{MPa}$.

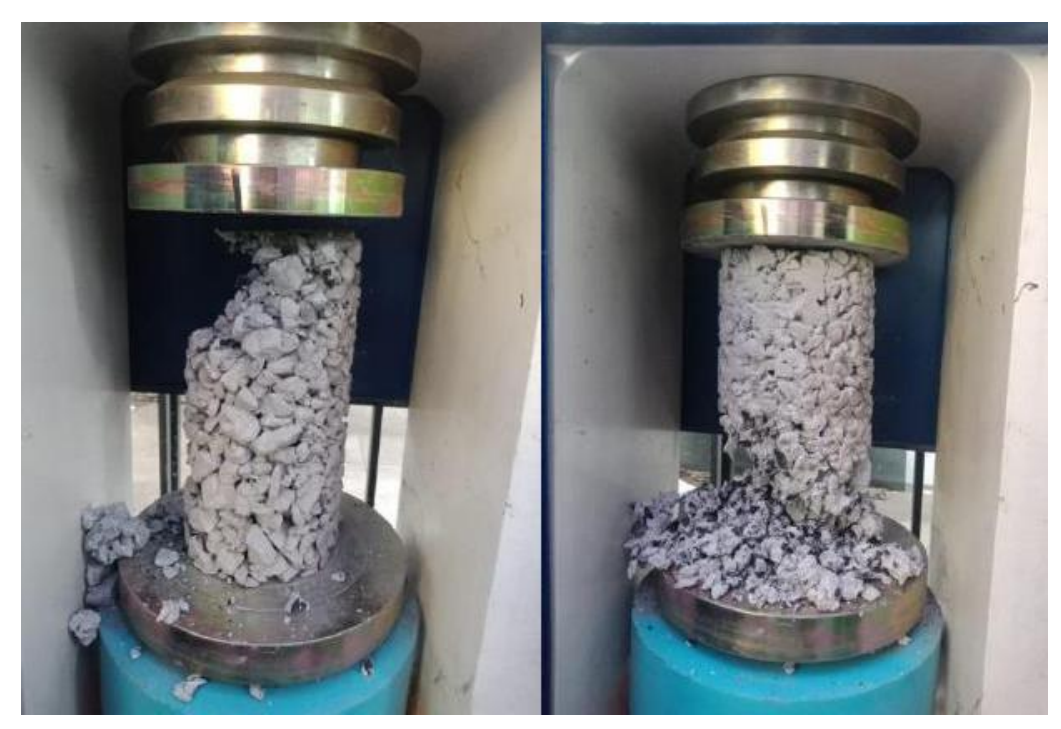

Gambar 3 Grafik perbandingan kuat tekan beton porous 
Saat dilakukan pengujian kuat tekan dapat diperhatikan pola retak yang terjadi ada berbagai macam menurut standar ASTM C 39/C 39M - 04a. Pola retakan yang terjadi dikarenakan penyebaran tegangan pada benda uji akibat proses ikat pegangan pada benda uji dan juga berpengaruh terhadap homogenitas agregat penyusun beton. Seperti terlihat pada gambar 3, pada model yang dilakukan perawatan perendaman dengan air PDAM dan air gambut berdasarkan hasil penelitian pola retak yang terjadi yaitu retakan pada ujung samping (tipe 5).

Bila dibandingkan dengan penelitian sebelumnya yang dilakukan oleh Trisnoyuwono, D. (2015), hasil pengujian pada beton porous dengan menggunakan agregat ALWA dan penambahan fly ash sebesar $10 \%$ dan $20 \%$ ini sama-sama dapat secara signifikan meningkatkan derajat workability beton segar dan kuat tekan beton porous. Pada penelitian ini beton porous menggunakan agregat lokal handil bakti dan diberikan perawatan menggunakan air PDAM dan air lahan gambut. Hasil pengujian memperlihatkan bahwa beton porous dengan penambahan fly ash saat diberi perawatan perendaman menggunakan air lahan gambut, terjadi peningkatan kuat tekan.

Pada hasil penelitian sebelumnya yang dilakukan oleh Trisnoyuwono, D. (2015), pada beton porous menggunakan dengan agreget ALWA dengan penambahan fly ash $10 \%$ - $20 \%$ dengan kuat tekan di atas $17 \mathrm{MPa}$ berdasarkan SNI 03-2461-2002 memenuhi syarat sebagai beton ringan untuk elemen struktural. Sedangkan pada penelitian ini beton porous yang menggunakan agregat kasar lokal Handil Bakti di kalimantan selatan dengan atau tanpa penambahan fly ash didapatkan kuat tekannya dibawah 17 Mpa berdasarkan SNI 03-6861.1-2002 memenuhi syarat untuk dibuat produk bata beton pejal (mutu II - mutu IV), bata beton berlubang (mutu I - IV).

\section{Kesimpulan}

Kuat tekan beton porous tanpa penambahan fly ash mengalami penurunan saat perawatan perendaman dengan air gambut. Pada beton porous tanpa penambahan fly ash yang diberi perawatan perendaman dengan air rawa mengalami penurunan kuat tekan beton sebesar 10,28\% dibandingkan dengan sampel beton porous yang direndam dengan air PDAM. Kuat tekan beton porous dengan penambahan fly ash 10\% yang direndam dengan air gambut yaitu sebesar 6,89 Mpa dan kuat tekan beton porous dengan penambahan fly ash $20 \%$ yang direndam dengan air gambut yaitu sebesar 7,85 Mpa. Dapat dilihat bahwa beton porous yang diberi penambahan fly ash dan diberi perawatan dengan menggunakan air lahan rawa mampu memperbaiki atau meningkatkan kinerjanya. Didapatkan kuat tekan dibawah 17 Mpa berdasarkan SNI 03-6861.1-2002 memenuhi syarat untuk dibuat produk bata beton pejal (mutu II - mutu IV), bata beton berlubang (mutu I IV). Pola retakan yang terjadi dikarenakan penyebaran tegangan pada benda uji akibat proses ikat pegangan pada benda uji dan juga berpengaruh terhadap homogenitas agregat penyusun beton. Pada model yang dilakukan perawatan perendaman dengan air PDAM dan air rawa gambut berdasarkan hasil penelitian pola retak yang terjadi yaitu retakan pada ujung samping (tipe 5).

\section{Ucapan Terima Kasih}

Ucapan terima kasih ditujukan kepada Lembaga Penelitian dan Pengabdian kepada Masyarakat dan dan Program Studi Teknik Sipil Fakultas Teknik Universitas Islam Kalimantan MAB Banjarmasin karena telah memberikan bantuan berupa dana dan laboratorium sehingga penelitian ini dapat dilaksanakan. Terimakasih pula kepada Pusat Kajian Infrastruktur Rawa yang telah bekerja bersama-sama sehingga penelitian dapat berjalan dengan lancar. 


\section{Daftar Pustaka}

ACI 318. (2008). Building Code Requirements for Structural Concrete ( ACI 318-08 ) (Vol.2007).

Agus, F., \& Subiksa, I. G. M. 2008. Lahan Gambut : Lahan Gambut : Potensi untuk Pertanian dan Aspek Lingkungan.

Eglinton, M. 2003. Resistance of Concrete to Destructive. Lea's chemistry of cement and concrete, 299.

Goyal, S., Kumar, M., Sidhu, D. S., \& Bhattacharjee, B. 2009. Resistance of Mineral Admixture Concrete to Acid Attack, 7(2), hal. 273-283.

Harber, P. 2005. Applicability of No-Fines Concrete as a Road Pavement, Dissertation towards the Degree of Bachelor of Engineering, Faculty of Engineering and Surveying, University of Southern Queensland, Australia.

Mehta, P. K., \& Monteiro, P. J. (2014). Concrete: microstructure, properties, and materials. McGraw-Hill Education.

M Saukani, S Arief . 2018. Karakteristik Termal Mortar Geopolimer Berbasis Abu layang dan Kaolin Alam- Jurnal Fisika Flux: Jurnal Ilmiah Fisika FMIPA

NRMC,2004,ConcreteinPractice-what,why, how (CIP 38-Pervious Concrete),USA.

NRMCA,2010,Pervious Concrete and Construction (International Concrete Sustainibility Conference Dubai, December 2010),USA

Nugraha, Paul \& Antoni 2007. Teknologi Beton, Penerbit Andi, Yogyakarta.

Olivia, M., Pradana, T., \& Sitompul, I. R. 2017. Properties of Plain and Blended Cement Concrete Immersed in Acidic Peat Water Canal Vol. 171, hal. 557-563. https://doi.org/10.1016/j.proeng.2017.01.372

Pradana, T., Olivia, M., \& Sitompul, I. R. 2013. Kuat Tekan dan Porositas Beton Semen OPC, PCC dan OPC POFA di Lingkungan Gambut, 3, hal. 1-10.

Saukani, M., Arief, S., Syahrillah, G. R. F., \& Hidayat, N. 2019. The Low Concentration of Sodium Hydroxide Influence on The Compressive Strength of Fly Ash/Natural KaolinBased Geopolymer. In IOP Conference Series: Materials Science and Engineering, Vol. 515, No. 1, hal. 012063.

Sebayang, S. 2010. Pengaruh Kadar Abu Terbang sebagai Pengganti Sejumlah Semen pada Beton Alir Mutu Tinggi, 14, hal 1-8.

Trisnoyuwono, D. 2015. Pengaruh Penambahan Fly Ash Terhadap Sifat Workability Dan Sifat Fisik-Mekanik Beton Non Pasir Dengan Agregat Alwa Asal Cilacap. Rekayasa Sipil, 9(1), hal. 29-36. 
